\title{
Towards transformational leadership: the nexus of emergency management systems in Canada
}

\author{
Denis H.J. Caro \\ Telfer School of Management, \\ University of Ottawa/Université d' Ottawa, \\ 55 Laurier Avenue East, \\ Ottawa, Ontario, K1N 6N5, Canada \\ Email: drcaro@uottawa.ca
}

\begin{abstract}
This qualitative research study explores the leadership challenges in emergency management systems in Canada. Complex adaptive systems theory forms the theoretical paradigmatic perspective of emergency events, such as mass emergencies, disasters and catastrophes. Thematic analysis of a key informant study of emergency leaders identified 12 key leadership capabilities. From the grounded theory methodological approach, a theory of transformational emergency systems leadership emerged and is posited. The findings and implications are discussed in light of theoretical implications for humanistic and technologically driven leadership; inter-sectorial collaborative networks; adaptive learning and training of future emergency leaders; and future international emergency management research.
\end{abstract}

Keywords: complex adaptive systems theory; emergency management systems; key informants; transformational leadership; qualitative research.

Reference to this paper should be made as follows: Caro, D.H.J. (2016) 'Towards transformational leadership: the nexus of emergency management systems in Canada', Int. J. Emergency Management, Vol. 12, No. 2, pp.113-135.

Biographical notes: Denis H.J. Caro is a Full Professor with the Telfer School of Management at the University of Ottawa in Ottawa, Canada. His alma mater is McGill University and he holds degrees in Mathematics, Management Information Systems and a Doctorate in Hospital and Health Administration from the School of Public Health at the University of Minnesota. He has extensive professional and teaching experience in Canada and the USA in emergency management, healthcare management and management information systems. Author of extensive scholarly publications, he is also winner of numerous awards in research, teaching and leadership.

\section{Introduction}

This qualitative study examines the results and implications of a key informant study of transformational leadership challenges in emergency management systems in Canada. It deploys a grounded theory methodology to examine the phenomenology of emergency leadership and to elucidate the leadership challenges from a systemic perspective. 
Thematic analysis of the key study responses point to 12 key leadership capabilities that promise to influence the evolution of emergency management systems. A theory of transformational emergency systems leadership is posited as an outcome of the grounded theory approach. The potential research and pragmatic systemic implications are then discussed and explored.

\section{Background}

Through a triangulation approach, this study proposes complex adaptive systems as the theoretical lens in which to understand emergency leadership. As background, the salient features of emergency management systems, transformational emergency leadership and the nature of complex adaptive systems are first described.

\subsection{Emergency management systems}

Emergency management systems are complex adaptive systems that respond to external environmental stimuli, in the form of range of emergency events (deMattos et al., 2012; Thomas et al., 2015). In the context of this study, emergencies refers to emergency events that include mass emergencies, disasters and catastrophes. Mass emergencies are relatively small-scale, common and largely predictable events that are managed with local and regional resources. Disasters are those that overwhelm regional resources and require multi-regional emergency responses and collaboration. Finally, catastrophes are extreme disasters that paralyse, or destroy, critical community infrastructures and require multi-regional, national and international responses. Emergency events may be biochemical (Malet and Korbitz, 2015); meteorological (Andreoni and Miola, 2015; Demiroz and Kapucu, 2012); sociogenic (Colbry et al., 2015; Rimstad and Sollid, 2015); technological (Guskova, 2012; Pandey and Kim, 2015); or topological (Kapucu, 2011; Momani, 2012) in nature. Emergency management systems engage multidisciplinary emergency professionals in collaborative efforts in its central mission to save lives, minimise injuries and maintain community integrity. Efficiency and effectiveness measures are at the heart of whether the goals and objectives are met (Cady, 2016). Emergency management systems operate on both horizontal and vertical planes. Table 1 summarises the key horizontal components all of which operate interdependently. This includes emergency mitigation and prevention, emergency preparedness, emergency response, emergency critical care and emergency recovery and rehabilitation.

The vertical plane includes a wide spectrum of socio-political organisational forms at different levels. These include emergency management organisations, healthcare facilities and institutions, municipal governments, regional authorities, provincial and territorial (or state) governments, national governments and international organisations. In normative times, emergency management systems tend to function as discrete, independent and loosely linked silos that focus primarily on internal care processes. Faced with chaotic and demanding emergency events, the effective horizontal and vertical integration of systems becomes compelling. This is in order to save lives, reduce injuries and protect the integrity and viability of communities. Emergency leadership is the lynchpin that integrates the system horizontally and vertically both in normative and 
chaotic emergency situations. Such leadership draws together disparate and diverse systemic resources and channels them into effective responses to external emergency events. Strategic leadership seeks to improve the efficiency and effectiveness of emergency systems through horizontal and vertical integration. In so doing, leaders encounter systemic challenges. This study seeks to elucidate the key leadership capabilities needed to meet these systemic challenges. These capabilities shed light on potential leadership development and directions in the evolution of emergency management systems.

Table 1 Horizontal emergency management systemic components and processes

\begin{tabular}{lllll}
\hline $\begin{array}{l}\text { Emergency } \\
\text { mitigation and } \\
\text { prevention }\end{array}$ & $\begin{array}{l}\text { Emergency } \\
\text { preparedness }\end{array}$ & $\begin{array}{l}\text { Emergency } \\
\text { response }\end{array}$ & $\begin{array}{l}\text { Emergency critical } \\
\text { care }\end{array}$ & $\begin{array}{l}\text { Emergency recovery } \\
\text { and rehabilitation }\end{array}$ \\
\hline $\begin{array}{l}\text { Environmental } \\
\text { scans }\end{array}$ & Business continuity & Evacuation & Care interventions & Aftercare services \\
$\begin{array}{l}\text { Forecasting } \\
\text { Mitigation } \\
\text { strategies }\end{array}$ & Contingency planning & Fire and rescue & Critical care nursing & Community recovery \\
$\begin{array}{l}\text { Prevention } \\
\text { Risk assessment }\end{array}$ & Supply resources & Paramedics & Emergency physicians & Home care \\
Scenario analysis & Recovery plans & Command centres & Emergency units & Recovery \\
& Response plans & Search/rescue & Logistics & Rehabilitation \\
& Simulation exercises & Transportation & Medical specialists & Social health \\
& Surge capacity plans & Triage & Primary hospital care & \\
& Threat analysis & & Trauma care units & \\
& & & Triage & Volunteer management
\end{tabular}

\subsection{Transformational emergency leadership}

Emergency leadership is essential in managing the dynamics of care providers, resources, patients and technologies along the horizontal and vertical continuum in emergency management systems. The extant literature points to a range of theoretical leadership paradigms, such as: adaptive models (Obolensky, 2014); authentic models (Fairchild et al., 2015); integral models (Larsson and Eid, 2012; Wilber, 2000); and transformational models (Larsson and Eid, 2012; Karaca et al., 2012). There is also a wide spectrum of systemic challenges that emergency leadership must confront. These include emergency response systems (Launder and Perry, 2014; Scotter et al., 2012); emergency logistics (Hilgers et al., 2013; Kapucu, 2011); critical care systems (deMattos et al., 2012; Meyer Junior et al., 2012); social recovery (Tan, 2013); and civil defence systems (Survila and Valickas, 2012). Not only must leaders be adept at assessing risks (Abrahamsson and Tehler, 2013), but they must promote cultures of prevention and safety (Taber and Taber, 2013), while maintaining systemic efficiency (Checkland, 2014). 
Effective transformational emergency leadership is crucial in all horizontal and vertical facets of emergency management systems (Eyre and Brady, 2013; Launder and Perry, 2014). As Rauner et al. (2012) pointed out effective emergency systems require the deployment of appropriate resources and supplies to support ongoing emergency operations. Rodríguez-Sánchez and Perea (2015) stressed that emergency leaders must engage multi-disciplinary professionals across socio-political spectrums to build cogent coalitions and relationships among diverse groups. As Urby and McEntire (2015) have underscored, leaders are transformational change agents who militate for systemic improvements throughout emergency management systems. Recent literature has given special attention to the importance of contextual aspects of emergency leadership (Charman, 2015; Larsson and Hyllengren, 2013) in promoting organisational resilience. (De Florio, 2014; Hills, 2015; Kantur and Iseri-Say, 2012; Moe, 2012). Strengthening accountability and leadership ethics is also deemed important in emergency leadership (Dean and Payne, 2013; Etkin and Timmerman, 2013; Faith, 2013). Emergency leaders must foster relational capital (Pedler and Attwood, 2014) to forge effective multi-organisational collaboration and intersectorial partnerships (Achour et. al., 2015; Cikaliuk, 2011; Lee and Fleming, 2015; Redshaw et al., 2015; Scotter et al., 2012; Waugh and Streib, 2006).

Another key leadership challenge is the effective deployment of innovative technologies to significantly enhance performance outcomes (Carmeli et al., 2010). Such technologies include: satellites for effective and efficient emergency response and rescue operations (Hascicek et al., 2014; Kose et al., 2015); wireless sensor and control technologies (Lundberg et al., 2012; Yang et al., 2012); and automated data mining and big-data systems that integrate data, images and sounds (Zagorecki et al., 2013). The literature also reports on leadership capability frameworks in Australia (Shannon, 2015), Canada (Dickson and Tholl, 2014; Levitt, 2014; Marchildon and Fletcher, 2016); and the UK (NHS Leadership Academy, 2013). These underscore the importance of continuous learning and for the need for international emergency leadership education and training (Edmonstone, 2015; Hunt et al., 2011).

\subsection{The theoretical optics of complex adaptive systems}

There are few qualitative research studies in emergency leadership that use the lens of complex adaptive systems (Caro, 2015). From this optic, emergency management systems are complex adaptive systems characterised by adaptive learning, emergent behaviour, phase transitions, scale-free activity and self-organisation (Paina and Peters, 2012). Such systems call for leadership thinking that embraces uncertainty, non-linearity and emergent behaviours and fosters adaptive spaces in which innovation thrives (Cohn, 2013). This is, in essence, what Obolensky (2014) calls complex adaptive leadership. Such leadership integrates systems thinking and innovative mindsets (Weberg, 2012) within networks with dynamic interdependencies and unpredictable outcomes. Transformational emergency leadership is adaptive in that operates in systemic contexts that are complex, non-linear and neither easily controlled nor predictable. Such leadership guides emergent behaviour, or the spontaneous development of new patterns of organisational behaviour that arise from the complex interactions of systemic components. Transformational emergency leadership is scale-free in that it is a locus that integrates systemic components to maintain cohesion and stability in the face of chaos. Such leadership initiates radical systemic changes at critical tipping points, or phase 
transitions. Emergency events have long-term strategic impacts that resonate through the system. Outcomes are influenced not only by initial emergency conditions, but also through transformational emergency leadership decisions made along the way.

\section{Methods}

Until recently, the extant literature has not reported on qualitative research studies on the perception of emergency professionals of leadership challenges in Canada. This qualitative study explores the phenomenology of emergency leadership through the use of grounded theory methodology and key informant analysis. Grounded theory is an inductive methodology and a systematic process of generating theory from conceptual categories and emerging thematic analysis (Charmas, 2014) and has been deployed in other studies (Burstrom et al., 2013; Seidel and Urquhart, 2013). The pretested research instrument was a key informant survey questionnaire to collect qualitative information from emergency leaders. This approach has been used in other settings (Hopia and Hakala, 2015; Leggio Jr., 2014). Moreover, this study deploys a triangulation approach, whereby leadership models and complex adaptive systems constructs are merged to form the theoretical framework. The salient points of the research design, study ethics and research instrument, study sample and respondents, grounded theory methodology and study limitations follow.

\subsection{Study design}

Using chain referral sampling, professional bodies were points of contact that graciously consented to issue invitations to their membership to participate in this study. These included the: Canadian Association of Fire Chiefs; Canadian College of Health Leaders; Canadian Association of Social Workers; and Canadian Information Processing Society. A six-week response time limit defined the purposive sample size and participation was voluntary and confidential. Only key informants who had an emergency background and were willing to share their perspectives within the study deadline of six weeks were included in the sample.

\subsection{Study ethics and research instrument}

An institutional research ethics committee on human subjects rigorously reviewed the proposed research study goals and objectives, study design and instruments. It fully endorsed this research design and instruments as meeting all confidentiality, privacy and ethical requirements deemed essential. This pretested research instrument consisted of a semi-structured questionnaire that focused on perceptions of diverse aspects of emergency leadership in Canada. Respondents could elect to complete the confidential research instrument tool online, or opt for a telephone interview, using the exact and identical questions of the online questionnaire. All respondents were given the option to respond either in English or French, both official languages in Canada. On a consensual basis, respondents then accessed a secured and private database with a reputable and trusted online survey firm. Qualified key informants who accessed the database were requested to read and sign a confidential statement of consent in the official language of their choice. Only then were the key informants allowed to have online access to 
the confidential questionnaire. There were 26 semi-structured open-ended questions in seven main areas. Aside from basic demographic information, the questions focused on: emergency experiences, leadership capabilities, perceived threats, emergency preparedness, systemic performance, future technologies and strategic partnerships. Table 2 provides a sample of the salient questions posed to key informants.

Table 2 Sample of thematic questions of key informant study on emergency management systems in Canada

\begin{tabular}{|c|c|}
\hline Thematic focus & Sample thematic questions \\
\hline \multirow{3}{*}{$\begin{array}{l}\text { Emergency } \\
\text { experiences }\end{array}$} & Describe the context of emergency service systems in which you work \\
\hline & Describe critical emergency encounters you have personally experienced \\
\hline & $\begin{array}{l}\text { Describe key emergency services systems lessons you have learnt } \\
\text { through experiences }\end{array}$ \\
\hline \multirow[t]{2}{*}{ Leadership capabilities } & $\begin{array}{l}\text { List and comment on the best leadership practices that promote systems } \\
\text { collaboration }\end{array}$ \\
\hline & $\begin{array}{l}\text { Describe critical leadership qualities in effective emergency } \\
\text { management systems }\end{array}$ \\
\hline Perceived threats & $\begin{array}{l}\text { List five emergency events that will threaten your community over the } \\
\text { next } 20 \text { years }\end{array}$ \\
\hline \multirow[t]{5}{*}{$\begin{array}{l}\text { Emergency } \\
\text { preparedness }\end{array}$} & $\begin{array}{l}\text { Comment on the extent to which the emergency management systems } \\
\text { work effectively }\end{array}$ \\
\hline & $\begin{array}{l}\text { List the accessibility and availability resource challenges in emergency } \\
\text { services }\end{array}$ \\
\hline & Indicate which emergency plans your organisation currently has in place \\
\hline & $\begin{array}{l}\text { Indicate whether your organisation actively tests and conducts } \\
\text { simulations annually }\end{array}$ \\
\hline & Comment on the level of emergency preparedness in your organisation \\
\hline Systemic performance & Describe up to five performance challenges encountered \\
\hline \multirow[t]{2}{*}{ Future technologies } & List technological developments you foresee over the next 20 years \\
\hline & $\begin{array}{l}\text { Comment on your vision of technological changes and its impact on } \\
\text { future emergency services systems }\end{array}$ \\
\hline Strategic partnerships & $\begin{array}{l}\text { List and comment on the best leadership practices that promote systems } \\
\text { collaboration }\end{array}$ \\
\hline
\end{tabular}

\subsection{Study sample and responses}

Purposive sample size was determined by the six-week response time limit and the defined study objectives. Within the study period, 103 questionnaires were received. Of these, 17 were disregarded, as they were not fully completed. In addition, seven key informants opted for a telephone interview. Given a total of 86 key informants from 76 organisations across Canada, the response rate was $83.5 \%$. This included: 28 leaders in healthcare facilities and hospitals; 25 government leaders in emergency management on either municipal, regional, provincial, or Federal (including defence) levels; 14 leaders in fire and rescue and paramedical services; 15 clinical leaders in emergency medicine, nursing and social work; and four leaders in private technology consulting firms. Of the total respondents, $89 \%$ were senior professionals with 10 or more years of 
emergency experience. Key informants provided copious textual responses, using the open-ended questionnaire format. The identical questionnaire was used for the telephone interviews. Here the researcher made detailed notes and verbally repeated the key points to the interviewee to clarify any responses.

\subsection{Grounded theory methodology}

Grounded theory is a qualitative research approach whereby response data is subjected to detailed systematic thematic analysis to generate new theory (Creswell 2013). Consonant with this approach, the results of all questionnaires were collected, analysed, summarised and ordered into major themes. The open-ended questionnaire and interviews evoked responses with meaningful descriptions of experiences and perceptions of emergency leaders. This data was subject to iterative processes of coding, memoing and integration. During coding, qualitative data was noted and categorised into themes, related to the initial core concept of emergency leadership. Repeated concepts developed and merged into substantive codes, which later formed the basis of new theory. Through memoing, thoughts and ideas were recorded, as they evolved and developed with time. In the integrative process, key emergency leadership elements were identified. Moreover, what emerged was new theory and insight gained into leadership of complex adaptive emergency systems. The emerging paradigm of transformational emergency systems leadership exposed the systemic challenges and was highly adaptable to new data that fine-tuned the model. The results suggested the importance of leadership in promulgating performance excellence, systemic integration and transformation of emergency management systems.

\subsection{Study limitations}

In the initial stages of the study, invitations to participate were sent to the Canadian Association of Chiefs of Police, the Paramedic Chiefs of Canada and the Canadian Nurses Association. However, none had responded by the required deadline of four weeks. However, the membership in the Canadian College of Health Leaders provided access to diverse public safety and care professionals across a vast spectrum of emergency leaders across Canada.

\section{Study results}

Consonant with a grounded theory approach, the first stages of theoretical memoing and analysis six interrelated significant constructs initially emerged. These included: scenario analysis; systemic integration of emergency management systems; collaborative coalitions, communities and networks; equanimity and composure; performance excellence and visions of future technological innovations. Table 3 provides the salient themes and a sample key informant comments that arose from the preliminary thematic analysis.

From further iterative thematic analysis of key informant responses, 12 key emergency leadership emerged. Moreover, based on a grounded theory methodology, this qualitative study gave rise to a proposed theory of transformational emergency systems leadership. These are presented below. 
Table 3 Salient highlights of key informant responses study of leadership of emergency management systems

\begin{tabular}{|c|c|}
\hline Thematic analysis & Salient key informant responses \\
\hline \multirow[t]{4}{*}{ Scenario analysis } & Escalation of regional, national and international threats \\
\hline & Continuous monitoring and situational awareness of \\
\hline & Risk mitigation strategies \\
\hline & Threats and vulnerability analysis \\
\hline \multirow{10}{*}{$\begin{array}{l}\text { Systemic integration of emergency } \\
\text { management systems }\end{array}$} & Community and social recovery \\
\hline & Ecology of emergencies \\
\hline & Emergency medicine \\
\hline & Emergency preparedness \\
\hline & Emergency command centres \\
\hline & Interoperability of telecommunication systems \\
\hline & Paramedicine \\
\hline & Physical, mental and social rehabilitation processes \\
\hline & Primary and secondary prevention strategies \\
\hline & Professional burnout and post-traumatic stress disorders \\
\hline \multirow{6}{*}{$\begin{array}{l}\text { Collaborative coalitions, } \\
\text { communities and networks }\end{array}$} & Cogent and stable collaboration \\
\hline & Community group support \\
\hline & Critical role of defence/military command units \\
\hline & $\begin{array}{l}\text { Engagement of regional, national and international } \\
\text { governance organisations }\end{array}$ \\
\hline & Mutual trust and professional respect \\
\hline & Stakeholder identification and analysis \\
\hline \multirow[t]{7}{*}{ Equanimity and composure } & Ambiguity with uncertainty in the face of fluid situations \\
\hline & Courage and humility \\
\hline & $\begin{array}{l}\text { Decisiveness under conditions of informational and sensory } \\
\text { overload }\end{array}$ \\
\hline & Objectivity, while maintaining caring and compassion \\
\hline & Personal ethics and integrity \\
\hline & Prior emergency and clinical experiences \\
\hline & Understanding human and socio-political limitations \\
\hline \multirow[t]{8}{*}{ Performance excellence } & Avoidance of wastages through walking on the frontlines \\
\hline & Adaptive learning culture \\
\hline & Lean engineering to leverage efficiency \\
\hline & Metrics to assess performance outcomes \\
\hline & Metrics to monitor operational and response efficiencies \\
\hline & $\begin{array}{l}\text { Outcomes-orientation with focus on saving lives and } \\
\text { reducing morbidities }\end{array}$ \\
\hline & $\begin{array}{l}\text { Performance analysis of emergency management } \\
\text { components }\end{array}$ \\
\hline & Promulgating a culture of continuous learning \\
\hline
\end{tabular}


Table 3 Salient highlights of key informant responses study of leadership of emergency management systems (continued)

\begin{tabular}{ll}
\hline Thematic analysis & Salient key informant responses \\
\hline Vision of future technological & Autonomic support to complement human perception and \\
innovations & understanding \\
& Big data support of unstructured data to create meaningful \\
& cognitive pictures \\
& Bringing the ER and surgical suite to the field \\
\hline
\end{tabular}

\subsection{Thematic analysis and leadership results}

The 12 key emergency leadership capabilities that emerged from the key informant analysis are described below.

\subsubsection{Caring and compassionate values}

A compelling caring vision that inspires and motivates others is one of the key hallmarks of emergency leaders. The key informants emphasised that caring values and compassion must be integral to the behaviours and decisions of emergency leaders. Leaders with compassion and humility inspire others to act ethically. Even in the heat of emergency events, victims and their families and all personnel must be treated with dignity and as having moral worth and innate rights. Honesty and integrity were also deemed of paramount importance. The ability to effectively communicate that vision and inspire others to collaborate and integrate emergency efforts is crucial. Deep empathy and compassion for others must inform and drive emergency decision-making.

\subsubsection{Authenticity}

Key informants underscored the importance of authentic leadership attributes, such as accessibility, adaptability, astuteness and emotional intelligence. Highly-developed social competencies were deemed very important, as were accountability and personal discipline. Key informants felt that personal integrity and professional ethics were essential for emergency leaders. High order communication skills were deemed crucial, as were professional competence and the ability to understand diverse multidisciplinary professional views. Situational awareness and self -awareness of personal limitations, as well as the ability to delegate authority, were also deemed important. Key informants also felt that authenticity, credibility and trustworthiness were also central in collaborating with all levels of governing authorities. All of these attributes helped to promote open communication, professional respect and mutual trust that are the foundation of effective emergency collaborative networks.

\subsubsection{Experiential knowledge}

Key informants underscored the importance of cogent knowledge and frontline experience with proven expertise in emergency management systems. Aside from a sound background of knowledge of emergency management systems, key informants emphasised training in operational and strategic management; emergency logistics and 
human resources management. It was not enough for emergency leaders to be proficient in planning, but also in strategy formulation and execution. Systemic knowledge, including an understanding of legal and sociopolitical contexts and governance, were also relevant. Cognitive skills, such as strategic and systems thinking in the face of complexity and pressing uncertainty, were also deemed important. Given technological innovations, key informants underscored the growing need for knowledge and training in emergency informatics and systems engineering to enhance the performance of emergency management systems.

\subsubsection{Relational capital}

Key informants recognised the need for relational capital of mutual trust and understanding across multi-disciplines and emergency organisations. Perceptual differences arise from diverse perspectives, priorities, processes and professional training across emergency management systems. Credible emergency leaders who emphasise shared caring values, goals and perspectives help overcome divergent views. These innate abilities foster credibility and trust that reinforce relational bonds. Key informants affirmed such relational capital promotes joint collaboration and foments positive horizontal and vertical integration of the system. They believed that social capital promulgates performance excellence and saves lives. They felt that mutual trust and open communication is the basis for better relationships with all levels of governing authorities. Moreover, they maintained that inter-sectorial relational capital enhances understanding and openness with the private technological sector, as well.

\subsubsection{Strategic communications}

The key informants unanimously agreed that the ability of emergency leaders to communicate effectively was a crucial leadership skill. Clarity in all communications facilitated positive interactions and prevented conflicts and misunderstandings. Also they emphasised the need to share vital emergency information effectively through integrated telecommunications infrastructures. The survivability of individuals and viability of organisations and communities ultimately depend on this. Moreover, they identified systems interoperability as one of the pressing challenges to effective communications across technological networks. They acknowledged that non-compliance with common telecommunication standards often originate from sociopolitical and jurisdictional issues. Systems interoperability, according to the key informants, poses one of the most intractable challenges to effective emergency management systems.

\subsubsection{Strategic collaboration}

Key informants maintained the need for effective collaborative networks both horizontally and vertically across emergency management systems. Effective collaboration leads to effective information and resource sharing that underpin effective emergency responses. Aside from emergency professionals and care providers, key informants stressed the need for collaboration with community groups, governing authorities (including the military), non-governmental organisations and the private sector. Key informants felt that emergency leaders had duties and responsibilities to work closely and proactively with all levels of governing authorities across jurisdictional lines. 
Effective collaboration requires cogent inter-organisational coalitions across multiple jurisdictions regionally, nationally and internationally. Collaboration and engagement of the private sector was deemed important in maintaining effective supply chain networks, coordinating joint emergency preparedness efforts and diffusing technological innovations.

\subsubsection{Performance excellence}

Key informants acknowledged that emergency professionals are often called to do more with less, sometimes at a cost of loss of life and higher long-term care costs to the system. Performance excellence is predicated on emergency efficiency (response, transport and discharge rates) and effectiveness (mortality, morbidity, recovery, professional and patient/family satisfaction rates). They felt that emergency leaders would do well by creating high reliability organisations in emergency management. Such organisations strive for performance excellence through continuous learning from errors and the deployment of a range of innovative technologies. Such organisations also apply a range of systems engineering tools to enhance systemic efficiency and effectiveness. Such techniques include activity-based costing, benchmarking, process analysis and reengineering, lean design, root cause analysis and simulations.

\subsubsection{Courage and equanimity}

The key informants emphasised that leaders must demonstrate courage and equanimity as they exercise their leadership duties and responsibilities in the 'heat of the battle'. They felt that such attributes inspire others to rise to the many challenges of emergency events. Moreover, they believed that spirited resolve and determination ultimately improves survivability, mitigates morbidity and reinforces organisational resilience in the face of emergencies. Repeatedly, the key informants underscored the need for adaptability, courage, discipline, equanimity, initiative and tenacity. These traits were also crucial they felt when proactively advocating positive systemic changes. Here also leaders must have courage and resolve when attacked and stonewalled by forces that have vested interests in the status quo.

\subsubsection{Emergency preparedness}

Key informants stressed that emergency leaders must engage individuals, organisations and communities in emergency preparedness as a social responsibility. This remains the vital core of planning and praxis of emergency management. They underscored the obligation of leaders to assess risks and analyse threats. Environmental perception, perspicacity, situational awareness and strategic analysis of a range of emergency scenarios are all integral to the praxis of emergency preparedness. Identifying and articulating clear and specific scenarios with probability estimations was deemed critical in formulating effective emergency preparedness strategies. Emergency response planning, disaster planning and recovery planning together with frequent testing and simulations were all viewed as essential. According to the key informants, systemic performance during actual emergency events depends upon the degree of emergency preparedness. Key informants also recognised that access to appropriate and essential resources through emergency logistics is important for the effective operational 
performance and sustainability of emergency management systems. Finally, key informants viewed resilience as important for psycho-social recovery of victims, families and communities from emergency events. Key informants perceived performance in actual emergency events depends upon the degree of emergency preparedness and its integration as an individual and social responsibility and value.

\subsubsection{Decisiveness}

Key informants stressed that decisiveness is of paramount importance for emergency leaders, even in the face of incomplete, or imperfect, information. They also felt that decisiveness and the ability to make tough decisions on the frontlines was important. They felt that leaders must carefully and expeditiously make balanced and rational decisions, based on input from diverse sources. They maintained that in the face of overwhelming time pressures and information overload, decisiveness in the face of emergency events was key in saving lives and reducing injuries. Prior experiences with emergencies and emergency training remain instrumental in overcoming the cognitive shock and information overload in such actual emergency events.

\subsubsection{Strategic foresight}

Strategic foresight requires systems thinking capabilities, precognition skills and astute situational awareness. Systems thinking requires that emergency management leaders look beyond the bounds of their institutions and adapt a regional systems perspective. Strategic thinking underscores the need for proactive precognition skills. Strategic foresight requires astute situational awareness and recognition that emergencies have the potential to compound and escalate into a domino effect. Key informants also stressed that cognition skills and the ability to think 'outside the box' beyond jurisdictional bounds was deemed important for emergency leaders.

\subsubsection{Transformational skills}

Transformational leadership underscores the ability to lead and change organisational cultures by inspiring others and innovating. Key informants recognised the central importance of transformational skills, such as change management, conflict resolution, innovative thinking and negotiation. They asserted that emergency leaders need to challenge the status quo in emergency management systems and introduce transformative changes that would improve the performance of emergency management systems. Transformational skills allow leaders to become effective change agents. Transformational leadership also coopts and engages communities to collaborate in the change process and strive for performance excellence in emergency management systems. A few key informants remarked that military experience enhanced transformational leadership skills.

\subsection{Towards the theory of transformational emergency systems leadership}

Using a grounded theory approach in this study, new theory emerged that sheds light into emergency management systems as complex adaptive systems. This is the theory of transformational emergency systems leadership, as illustrated in Figure 1. 
Figure 1 The emerging theory of transformational emergency systems leadership (see online version for colours)

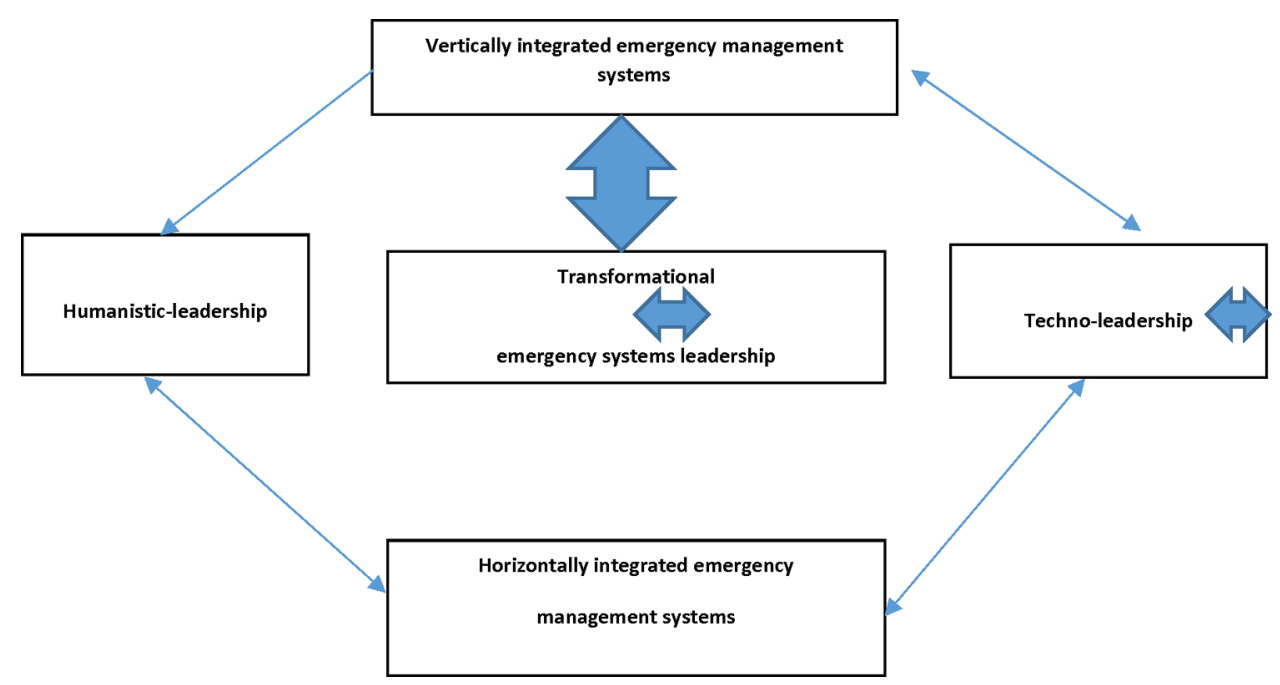

The theoretical premise is that transformational emergency leadership is a singular construct with identifiable capabilities that mediates and drives emergency management systems through a horizontal and vertical planes. Moreover, the emergency leadership dichotomises into two key components: humanistic leadership and techno-leadership. The humanistic leadership has inherently human and social capabilities, such as authenticity, caring and compassionate values, relational capital, courage and equanimity, strategic foresight and transformative skills. The techno-leadership has properties that have the potential to be leveraged and supported through innovative technologies. These capabilities include emergency preparedness, experiential knowledge, performance excellence, strategic communications, collaboration and decisiveness, all of which are potentially enhanced through the use of innovative technologies. There is a symbiotic and synergetic relationship of humans and technology through the mediation of transformational emergency systems leadership. Although emergency leadership is increasingly dependent on innovative technologies, the humanistic leadership capabilities must remain paramount.

\section{Discussion}

There are four potential implications proposed from this emergency leadership study. These include: the implications of the theory of transformational emergency systems leadership; inter-sectorial collaborative networks; integrative learning systems of transformational leadership; and potential future emergency management systems research.

\subsection{Towards transformational emergency systems leadership}

Transformational leadership forms the nexus of performance excellence in emergency management. Such leadership is also a catalyst for transformational changes in the 
drive for positive systemic outcomes. A complex adaptive systems perspective of transformational leadership is posited to best reflect the nature emergency management systems. It focuses on synergistic decision-making and transformation in highly complex, dynamic and uncertain contextual environments. Such environments require high-order leadership capabilities of coalition building, flexibility, foresight and vision, innovation, negotiation and persuasive abilities. All this is essential in orchestrating systemic processes and fostering performance excellence of a panoply of emergency professionals across diverse organisations. Transformational leadership underscores the importance of caring and compassionate values that preserve and uphold health, well-being and communal integrity as crucial.

As mentioned in the results section, the theory of transformational emergency systems leadership emerged from a grounded theory approach. In particular, it proposes that the leadership dichotomises into two highly interrelated components: humanistic leadership and techno-leadership. Humanistic leadership underscores the need for authentic leaders who are astute, empathic and possess cogent insight into human behaviours. Such leaders build relational and social capital upon which cogent collaboration is forged. Ethical behaviour, honesty and integrity are of paramount importance. Caring and compassionate leadership must prevail as an inspiration to all in the throes of emergencies. Courage and equanimity are also essential qualities of emergency leaders. Finally, humanistic leaders constantly challenge the status quo and strive for transformational changes in the best interests of the public.

Techno-leadership is leveraged through innovative technologies. Emergency preparedness remains the vital core of planning and the essential praxis of emergency management. It requires access to vital emergency resources and supply chain networks. Effective strategic communications requires message clarity and repetition. Collaborative networks are key in promoting proactive emergency management strategies across jurisdictional and organisational boundaries. Moreover, these emergency networks must engage community organisations, military units, non-governmental organisations and private emergency supply enterprises. Innovative technologies are also critical in enhancing and leveraging leadership underscoring its symbiotic and synergetic relationship with humans. Technologies such as: 'big-data' storage, cloud computing, collaborative web technologies, expert decision support systems, gaming simulations, intelligent systems, learning technologies, nanotechnologies, neural networks, sensor technologies and virtualisation facilitate the integration of critical environmental and emergency information sharing. Strategic and operational emergency decision-making are enhanced through autonomic systems, data analytics, expert decision support systems and intelligent systems. Advanced telecommunication systems, collaboration technologies and social media facilitate the building and coalescing critical emergency infrastructures regionally, nationally and internationally. Novel technologies, such as advanced learning technologies, robotics and simulation systems, enhance and facilitate shared learning regionally, nationally and internationally.

Emergency management systems are highly dynamic complex adaptive systems in which transformational leadership is the systemic lodestar. All of these components are interdependent and influence each other as they evolve and transform. Emergency leaders essentially orchestrate the high-order choreography of the plethora of emergency professionals and technologies across emergency management systems. There is a symbiotic and synergetic relationship of humans and technology through the mediation of transformational emergency systems leadership. Although emergency leadership is 
increasingly dependent on innovative technologies, the humanistic leadership capabilities must remain paramount.

\subsection{Towards inter-sectorial collaborative networks}

The study points to the potential of inter-sectorial collaboration between the public emergency sector and private technological sectors respectively. Such collaboration fosters crucial access to dependable resource and supply chain networks and promotes emergency preparedness praxis as social community responsibility. Such collaborative networks call for dynamic, stable and mutually beneficial strategic relationships that promulgate learning, growth and innovation in the public interest. Transformational emergency leaders must encourage and engage in continuous and productive dialogues among all parties to make effective collaboration a reality.

The implementation of high-reliability emergency organisations is one of the innovative strategies that emergency leaders as change agents may promulgate. Systemic improvements and adaptability are the hallmarks of such organisations that seek to prevent and mitigate the impact of emergency events. Transformational leaders are potential catalysts to transform systems through a panoply of promising technologies that might redefine the work of future emergency professionals. Such innovations appear to include: autonomic computers; 'big-data' analytical machines; driverless emergency vehicles; drones; holographic applications; intelligent expert technologies; robotics; advanced sensor technologies; tele-surgery and virtualisation technologies. Investigation into the potential application of these technologies require high-order inter-sectorial collaboration between the public emergency and private technology sectors. For this to happen, transformational emergency leaders must focus on proactively building relational capital with the private technological sector. Here governing organisations may be catalysts to facilitate these inter-sectorial coalitions, as innovations diffuse through societies.

At the same time, transformational emergency leaders recognise the Realpolitik of socio-political and economic environments present ongoing systemic constraints and challenges. In Canada, as in many other nations, public governance systems determine financing levels and resource allocation that shapes the strategic direction of emergency management systems. The proactive engagement and support of governing authorities is key to effective strategic collaborative networks and systemic performance. Cogent transformational leadership in public governance constitutes an essential element that impacts systemic effectiveness locally, regionally, nationally and internationally. Whether through governance legislation and regulations, public financing, technological standards and knowledge management, ultimately public governing forces are important in the positive transformation of emergency management systems. Thus, transformational leaders in emergency management systems are often limited and stymied in what changes they can effect, unless there is also transformational leadership within the public governance domain ipso facto.

\subsection{Towards integrative learning systems of transformational leadership}

Continuous integrative systemic learning, improvement and adaptability are hallmarks of high performing emergency management systems. It is central in the quest for 
higher orders of systemic effectiveness, efficiency and performance. All learning processes are directed towards defined goals and objectives and are actualised through knowledge acquisition, critical thinking and transformative leadership skills. This study points to the need for transformational leadership development and training of the highest-order. Adaptive and continuous learning of such leaders in the emergency domain remains a challenge. On the basis of this study, Table 4 proposes the knowledge bases, cognitive skills and leadership skills needed for emergency leaders for this century. It also suggests learning processes to integrate knowledge, thinking and leadership skills.

Table 4 Transformational emergency systems leadership learning systems

\begin{tabular}{ll}
\hline Learning foci and modalities & Learning components \\
\hline Knowledge bases & Community medicine and healthcare \\
& Data analytics \\
& Disaster management and recovery \\
& Emergency health and medical care \\
& Emergency informatics \\
& Emergency logistics \\
& Emergency operations management \\
& Emergency response systems \\
& Emergency telecommunications \\
& Environmental health and scanning \\
& Human resource management \\
& International emergency management \\
& Leadership theory and principles \\
& Organisational behaviours \\
Risk assessment techniques \\
Socio-political governance and legal systems \\
Strategic management and strategy formulations \\
Systems engineering \\
Complex adaptive systems thinking \\
Ethical paradigms and thinking \\
High level communication skills \\
Intercultural sensitivity training \\
Scenario analysis \\
Self-awareness \\
Situation awareness \\
Strategic foresight \\
Technological assessment \\
\hline Cognitive skills & \\
\hline
\end{tabular}


Table 4 Transformational emergency systems leadership learning systems (continued)

\begin{tabular}{ll}
\hline Learning foci and modalities & Learning components \\
\hline Transformational leadership capabilities & Change management \\
& Collaboration networking building \\
& Conflict resolution \\
& Continuous learning skills \\
& Negotiation skills \\
& Transformational leadership training \\
& Case analysis \\
Learning modalities & Continuous professional development and learning \\
& Emergency field exercises \\
& Experiential knowledge sharing across multi-disciplines \\
& Interdisciplinary workshops \\
& Simulations \\
& Three-dimensional virtual gaming \\
\hline
\end{tabular}

Emergency leadership programs should require mandatory exposure to a range of emergencies in collaboration with a panoply of emergency professionals across the system. Proven expertise and personal leadership attributes might be important criteria for entrance to higher education for future transformational leaders. These leaders must be of excellent physical and mental conditioning to fully confront the demands and rigours demands of transformational leadership in the emergency management systems. Moreover, the service ethic of caring and compassion towards people is essential. Rigorous simulations and multi-professional intensive exercises, based on airline pilot or military pedagogical approaches, might be in order.

The International Emergency Management Association offers excellent professional development programs, such as the Certified Emergency Management designation. In addition, there is a number of national institutions that train emergency managers, including: Emergency Management Australia; the Institute of Emergency Management, which is linked with the Federal Emergency Management Agency (FEMA) in the USA; the National Institute of Disaster Management (India); the National Institute of Emergency Management which is linked with the Chinese Academy of Governance; and Public Safety Canada. The United Nations Office for the Coordination of Humanitarian Affairs (OCHA) also has emergency management training programs. Moreover, professional bodies in emergency medicine, emergency nursing and emergency social work also offer a panoply of excellent specialist and leadership development opportunities. In all of these leadership training initiatives, it is important to incorporate a multidisciplinary approach across the horizontal and vertical spectra of integrated emergency management systems. In essence, transformational emergency systems leadership learning and training is needed. Complex adaptive systems thinking lies at the heart of emergency transformational leadership development. The end result is that leaders with professional backgrounds in emergency medicine, medical social work, emergency nursing, paramedic, fire and rescue services, police services and public governance have a deep understanding of the essential systemic contributions of each. These professionals need to think and learn together as emergency professionals, before 
they can effectively collaborate together. From these dynamic learning interactions, true transformational leaders will emerge.

\subsection{Towards future emergency management systems research}

Emergency management systems research is never an end unto itself. Rather it promises to elucidate ways to effectively deploy new emergency knowledge and innovative technologies for the betterment of humankind. The increase of the numbers and magnitude of future emergency events in this century will no doubt increase the need for further emergency management research. This is as a means to prevent their occurrence or mitigate their deleterious impacts on victims, professionals and communities. Qualitative research using a grounded theory approach and thematic analysis hold promise for other investigations for examining perceptions of emergency leaders on a wide range of potential areas. Such studies could focus on areas such as: disaster management and recovery, emergency informatics, emergency response systems, emergency supply logistics, humanitarian relief systems, international collaborative networks, and post-traumatic stress disorders. The theory of transformational emergency systems leadership holds promise for further leadership research in other emergency settings internationally. Potential qualitative leadership studies could potentially include: air paramedical services, coroner services, emergency refugee care, field hospitals and indigenous peoples emergency care systems. Emergency leadership studies in diverse socio-cultural and socio-political contexts hold promise. Such qualitative research studies might be encouraged in emergency settings in national contexts, such as: Brazil, China, Columbia, the Congo, India, Indonesia, Iran, Japan, Mexico, Nigeria and Russia. Emergency management systems research on inter-sectorial collaboration with governments and the private sector are also of great potential. Finally, more studies into emergency informatics, innovative technologies and systems engineering all promise to revolutionise emergency management systems and represent another titanic area of future research investigation.

\section{Conclusion}

Transformational emergency systems leadership is the lodestar of evolving emergency management systems. Relational capital builds viable strategic collaborations that thrive horizontally and vertically in the system. Systemic efficiencies and effectiveness depend on leaders with considerable relational capital and who exercise transformational leadership. This key informant study identified 12 key properties of emergency leaders in a Canadian context. It is suggested that these properties may well be applicable to other international contexts. It is likely that humanistic leadership such as authenticity, strategic foresight, caring and compassion, courage and equanimity, relational capital and transformational skills transcend national borders. Moreover, calls for enhanced communications, collaboration, decisiveness, experiential knowledge and emergency preparedness will continue to resonate with emergency professionals around the world. The growing technological complementary of leadership processes will evolve and gain a greater foothold, as nations focus on more sustainability. The world of emergency management systems is fraught with complex and competing priorities and challenges. Yet transformational emergency systems leadership with its emphasis on innovative 
changes and the upholding cogent caring and public service values will continue to be of relevance. The frequency and magnitude of emergency events will undoubtedly increase. Demographic changes and socio-political chaos and turmoil will increase exposure to growing ranges of threats in vulnerable environments. Ultimately, it is the public themselves who will judge whether emergency management systems have met performance expectations. They will hold leaders to account come the time of ultimate tests of mass emergencies, disasters and catastrophes. Leaders must not be found wanting. No longer do emergency events end at the door of hospital emergency departments. Rather they find closure when victims, emergency professionals and communities have fully recovered from the ordeals experienced physically, emotionally and socially (Caro, 2015). Internationally, in the face of resource constraints, limited political will and wavering public support, sustainable emergency management systems will continue to require cogent transformational leadership. Such leadership will be crucial in the future evolution of effective emergency management systems. In effect, transformational emergency system leadership seeks the engagement, actualisation and harmonisation of positive policies, strategies and systems for the common good across regional, national and global communities for both present and future generations. Ultimately, all this is for the common benefit of humankind in face of the ravages of local, regional, national and international emergency scenarios.

\section{Competing interests}

There are no competing interests in this paper.

\section{Author contributions}

The entire manuscript is the result of the sole author's research and work.

\section{Acknowledgements}

The author deeply appreciates the time and support of all the participants in this key informant study. In particular he is grateful to the Canadian College of Health Leaders, the Association of Fire Chiefs of Canada, the Association of Social Workers of Canada and the Canadian Information Processing Society for their kind cooperation and assistance.

\section{References}

Abrahamsson, M. and Tehler, H. (2013) 'Evaluating risk and vulnerability assessments: a study of the regional level in Sweden', International Journal of Emergency Management, Vol. 9, No. 1, pp.76-92, http://dx.doi.org/10.1504/IJEM.2013.054106.

Achour, N., Pascale, F., Soetanto, R. and Price, A.D.F. (2015) 'Healthcare emergency planning and management to major hazards in the UK', International Journal of Emergency Management, Vol. 11, No. 1, pp.1-19, http://dx.doi.org/10.1504/IJEM.2015.069514. 
Andreoni, V. and Miola, A. (2015) 'Climate change and supply-chain vulnerability: Methodologies for resilience and impacts quantification', International Journal of Emergency Services, Vol. 4, No. 1, pp.6-26, http://dx.doi.org/10.1108/IJES-09-2014-0012.

Burstrom, L., Starrin, B., Engstrom, M. and Thulesius, H. (2013) 'Waiting management at the emergency department - a grounded theory study', BMC Health Services Research, Vol. 13, No. 1, p.95, http://dx.doi.org/0.1186/1472-6963-13-95.

Cady, P. (2016) 'A system of system lenses for leadership decision-making', Healthcare Management Forum, Vol. 29, No. 1, pp.8-11, http//dx.doi.org/10.1177/0840470415614412.

Carmeli, A., Gelbard, R. and Gefen, D. (2010) 'The importance of innovation leadership in cultivating strategic fit and enhancing firm performance', The Leadership Quarterly, Vol. 21, No. 3, pp.339-349.

Caro, D.H.J. (2015) 'Code red: Towards authentic transformational leadership of emergency management systems', Journal of Hospital Administration, Vol. 4, No. 5, pp.1-12, http//dx.doi.org/10.5430/jha.v4n5p.

Charman, S. (2015) 'Crossing cultural boundaries: Reconsidering the cultural characteristics of police officers and ambulance staff', International Journal of Emergency Services, Vol. 4, No. 2, pp.158-176, http//dx.doi.org /10.1108/IJES-07-2014-0011.

Charmas, K. (2014) Constructing Grounded Theory, Sage Publications, London.

Checkland, K. (2014) 'Leadership in the NHS: Does the Emperor have any clothes?', Journal of Health Services Research and Policy, Vol. 19, No. 4, pp.253-256, http://dx.doi.org/ $10.1177 / 1355819614529101$.

Cikaliuk, M. (2011) 'Cross-sector alliances for large-scale health leadership development in Canada: lessons for leaders', Leadership Health Services, Vol. 24, No. 4, pp.281-294, $\mathrm{http} / / \mathrm{dx}$. doi.org/10.1108/17511871111172330.

Cohn, J. (2013) 'Leading healthcare in complexity', Nursing Leadership, Vol. 27, No. 4, pp.52-64.

Colbry, S., McLaughlin, E., Womack, V. and Gallagher, J. (2015) 'Understanding the dynamic role of leadership and followership in conflict regions: cooperative action, courage and shared sacrifice', Journal of Leadership, Accountability and Ethics, Vol. 12, No. 4, pp.145-160.

Creswell, J.W. (2013) Qualitative Inquiry and Research Design: Choosing among Five Approaches, Sage Publications, Thousand Oaks.

De Florio, V. (2014) 'Quality indicators for collective systems resilience', Emergence: Complexity and Organization, Vol. 16, No. 3, pp.65-104.

Dean, M.D. and Payne, D.M. (2013) 'Disaster management: an ethical review and approach', International Journal of Emergency Management, Vol. 9, No. 2, pp.113-126, http://dx.doi.org/10.1504/IJEM.2013.055157.

deMattos, P.C., Miller, D.M. and Park, E.H. (2012) 'Decision making in trauma centers from the standpoint of complex adaptive systems', Management Decision, Vol. 50, No. 9, pp.1549-1569.

Demiroz, F. and Kapucu, N. (2012) 'The role of leadership in managing emergencies and disasters', European Journal Economic and Political Studies, Vol. 5, No. 1, pp.91-101.

Dickson, G. and Tholl, B. (2014) Bringing Leadership to Life in Health: LEADS in a Caring Environment: A New Perspective, Springer-Verlag, London.

Edmonstone, J. (2015) 'Developing healthcare leaders and managers: course-based or practicebased?', International Journal of Healthcare, Vol. 1, No. 1, pp.9-12, http://dx.doi.org/ 10.5430/ijh.v1n1p9.

Etkin, D. and Timmerman, P. (2013) 'Emergency management and ethics', International Journal of Emergency Management, Vol. 9, No. 4, pp.277-297, http//dx.doi.org/10.1504/ IJEM.2013.059866. 
Eyre, A. and Brady, K. (2013) 'Addressing psychosocial and community recovery in emergency management', International Journal of Emergency Services, Vol. 2, No. 1, pp.60-72, http://dx.doi.org/10.1108/IJES-09-2012-0037.

Fairchild, R., Ferng, S.F. and Zwerner, R. (2015) 'Authentic leadership practices informed by a rural hospital study', Journal of Hospital Administration, Vol. 4, No. 2, pp.54-63, http//dx.doi.org/10.5430/jha.v4n2p54.

Faith, K.E. (2013) 'The role of values-based leadership in sustaining a culture of caring', Healthcare Management Forum, Vol. 26, No. 1, pp.6-10, http//dx.doi.org/10.1016/ j.homf.2012.07.001.

Guskova, A.K. (2012) 'Medical consequences of the Chernobyl accident: aftermath and unsolved problems', Atomic Energy, Vol. 113, No. 2, pp.135-142, http://dx.doi.org/10.1007/s10512012-9607-5.

Hascicek, Y.S., Kose, S. and Koytak, E. (2014) 'An overview of the use of satellite navigation for disaster management and emergency response', International Journal of Emergency Management, Vol. 10, No. 1, pp.1-27, http://dx.doi.org/10.1504/IJEM.2014.061658.

Hilgers, M.G., Elrod, C.C. and Kampunzu, J.B. (2013) 'Supply chain dynamics relief of sudden-onset disasters', International Journal of Emergency Management, Vol. 9, No. 2, pp.93-112, http://dx.doi.org/10.1504/IJEM.2013.055149.

Hills, M. (2015) 'Assuring organisational resilience with lean scenario-driven exercises', International Journal of Emergency Services, Vol. 4, No. 1, pp.37-49, http//dx.doi.org/ 10.1108/IJES-09-2014-0019.

Hopia, H. and Hakala, A. (2015) 'Finnish social and health care professionals' perspective of the future', International Journal of Healthcare, Vol. 2, No. 1, pp.12-20, http://dx.doi.org/ 10.5430/ijh.v2n1p12.

Hunt, J.C., Gruenwoldt, E. and Lyster, A.H. (2011) 'Engaging the next generation of health leaders: perspectives of emerging health leaders', Healthcare Management Forum, Vol. 24, No. 1, pp.4-8, http://dx.doi.org/10.1016/j.hcmf.2010.12.001.

Kantur, D. and Iseri-Say, A. (2012) 'Organizational resilience: a conceptual integrative framework', Journal of Management and Organization, Vol. 18, No. 6, pp.762-773, http://dx.doi.org/ 10.1017/S1833367200000420.

Kapucu, N. (2011) 'Collaborative governance in international disasters: Nargis cyclone in Myanmar and Sichuan earthquake in China cases', International Journal of Emergency Management, Vol. 8, No. 1, pp.1-25, http://dx.doi.org/10.1504/IJEM.2011.040395.

Karaca, H., Kapucu, N. and Van Wart, M. (2012) 'Examining the role of transformational leadership in emergency management: the case of FEMA', Risks, Hazards and Crisis in Public Policy, Vol. 3, No. 3, pp.19-37, http://dx.doi.org/10.1002/rhc3.10.

Kose, S., Koytak, E. and Hascicek, Y.S. (2012) 'An overview on the use of satellite communications for disaster management and emergency response', International Journal of Emergency Management, Vol. 8, No. 4, pp.350-382, http://dx.doi.org/10.1504/ IJEM.2012.051647.

Larsson, G. and Eid, J. (2012) 'An idea paper on leadership theory integration', Management Research Review, Vol. 35, No. 3, pp.177-191, http://dx.doi.org/10.1108/01409171211210109.

Larsson, G. and Hyllengren, P. (2013) 'Contextual influences on leadership in emergency type organisations', International Journal of Organizational Analysis, Vol. 21, No. 1, pp.19-37, http://dx.doi.org/10.1108/19348831311322515.

Launder, D. and Perry, C. (2014) 'A study identifying factors influencing decision making in dynamic emergencies like urban fire and rescue settings', International Journal of Emergency Services, Vol. 3, No. 2, pp.144-161, http//dx.doi.org /10.1108/IJES-06-2013-0016.

Lee, S. and Fleming, R.T. (2015) 'Collaborative disaster management in local governments: perception, performance, and challenges', International Journal of Emergency Management, Vol. 11, No. 4, pp.343-355, http://dx.doi.org/10.1504/IJEM.2015.074048. 
Leggio Jr., W.J. (2014) 'The state of leadership education in emergency medical services: a multi-national qualitative study', Prehospital Disaster Medicine, Vol. 29, No. 5, pp.1-6, http://dx.doi.org/10.1017/S1049023X14000867.

Levitt, D. (2014) 'Ethical decision-making in a caring environment: the four principles and LEADS', Healthcare Management Forum, Vol. 27, No. 7, pp.105-107.

Lundberg, J., Törnqvist, E. and Nadjm-Tehrani, S. (2012) 'Resilience in sensemaking and control of emergency response', International Journal of Emergency Management, Vol. 8, No. 2, pp.99-122, http://dx.doi.org/10.1504/IJEM.2012.046009.

Malet, D. and Korbitz, M. (2015) 'Bioterrorism and local agency preparedness: results from an experimental study in risk communication', Journal of Homeland Security and Emergency Management, Vol. 12, No. 4, pp.861-873, http://dx.doi.org/10.1515/jhsem-2014-0107.

Marchildon, G.P. and Fletcher, A.J. (2016) 'Prioritizing health leadership capabilities in Canada: testing LEADS in a caring environment', Healthcare Management Forum, Vol. 29, No. 1, pp.19-22, http://dx.doi.org /10.1177/0840470415602744.

Meyer Junior, V., Pascucci, L. and Murphy, J.P. (2012) 'Implementing strategies in complex systems: lessons from Brazilian hospitals', BAR-Brazilian Administration Review, Vol. 9 (SPE), pp.19-37.

Moe, T.L. (2012) 'Aiming for resilience and adaptation in managing environment: an emerging environmental and emergency leadership in the twenty-first century', International Journal of Disaster Resilience in the Built Environment, Vol. 3, No. 1, pp.42-51, http://dx.doi.org/ 10.1108/17595901211201123.

Momani, N.M. (2012) 'Integrated framework for earthquake consequences management', Disaster Prevention and Management: An International Journal, Vol. 21, No. 2, pp.184-205.

NHS Leadership Academy (2013) Healthcare Leadership Model: The Nine Dimensions of Leadership Behavior, NHS Leadership Academy, Leeds, p.5.

Obolensky, N. (2014) Complex Adaptive Leadership: Embracing Paradox and Uncertainty, 2nd ed., Gower Publishing, Farnham.

Paina, L. and Peters, D.H. (2012) 'Understanding pathways for scaling up health services through the lens of complex adaptive systems', Health Policy and Planning, Vol. 27, No. 5, pp.365-373, http//dx.doi.org/10.1093/heapol/czr054.

Pandey, A. and Kim, H.S. (2015) 'Assessment of radiation safety perimeter for a radiological emergency management involving RDD explosion in metropolitan area, based on Gaussian dispersion model', International Journal of Emergency Management, Vol. 11, No. 4, pp.320-329, http://dx.doi.org/10.1504/IJEM.2015.074046.

Pedler, M. and Attwood, M. (2011) 'How can action learning contribute to social capital? 'Action Learning: Research and Practice, Vol. 8, No. 1, pp.27-39, http://dx.doi.org/ 10.1080/14767333.2011.549323.

Rauner, M.S., Scaffhauser-Linzatti, M.M. and Niessner, H. (2012) 'Resource planning for ambulance services in mass casualty incidents: a DES-based policy model', Health Care Management Science, Vol. 15, No. 3, pp.254-268.

Redshaw, S., Ingham, V. and Loftus, S. (2015) 'Emergency decision making: an exploration of tensions between communities of practice', International Journal of Emergency Management, Vol. 11, No. 1, pp.62-75.

Rimstad, R. and Sollid, S.M.J. (2015) 'A retrospective observational study of medical incident command and decision-making in the 2011 Oslo bombing', International Journal of Emergency Medicine, Vol. 8, No. 4, pp.1-10, http//dx.doi.org/10.1186/s12245-015-0052-9.

Rodríguez-Sánchez, A.M. and Perea, M.V. (2015) 'The secret of organisation success: a revision on organisational and team resilience', International Journal of Emergency Services, Vol. 4, No. 1, pp.27-36, http://dx.doi.org/10.1108/IJES-09-2014-0018.

Scotter, J.R.V., Pawlowski, S.D. and Cu, T.D. (2012) 'An examination of interdependencies among major barriers to coordination in disaster response', International Journal of Emergency Management, Vol. 8, No. 4, pp.281-307, http://dx.doi.org/10.1504/IJEM.2012.051640. 
Seidel, S. and Urquhart, C. (2013) 'On emergence and forcing in information systems grounded theory studies: the case of Strauss and Corbin', Journal of Information Technology, Vol. 28, No. 3, pp.237-260, http://dx.doi.org/10.1057/jit.2013.17.

Shannon, E.A. (2015) 'Health LEADS Australia: implementation and integration into theory and practice', Asia Pacific Journal of Health Management, Vol. 10, No. 1, pp.56-62.

Survila, A. and Valickas, A. (2015) 'Emergency management: guidelines for emergency manager's competency model formation', Public Policy and Administration, Vol. 14, No. 2, pp.265-278.

Taber, M.J. and Taber, N. (2013) 'Exploring emergency response: theories of communities of practice, safety cultures, situation awareness and tacit knowledge', International Journal of Emergency Management, Vol. 9, No. 1, pp.46-58, http//dx.doi.org/10.1504/ IJEM.2013.054096.

Tan, N.T. (2013) 'Emergency management and social recovery from disasters in different countries', Journal of Social Work in Disability and Rehabilitation, Vol. 12, Nos. 1-2, pp.8-18.

Thomas, C.W., Corso, L. and Monroe, J.A. (2015) 'The value of the 'system' in public health services and systems research', American Journal of Public Health, Vol. 04, No. 105, pp.147-S149.

Urby, H. and McEntire, D.A. (2015) 'Emergency managers as change agents: recognizing the value of management, leadership, and strategic management in the disaster profession', Journal of Emergency Management, Vol. 13, No. 1, pp.37-51, http://dx.doi.org/10.5055/jem.2015.0216.

Waugh, W.L. and Streib, G. (2006) 'Collaboration and leadership for effective emergency management', Public Administration Review, Vol. 66, Supplement 1, pp.131-140, http://dx.doi.org/10.1111/j.1540-6210.2006.00673.x.

Weberg, D. (2012) 'Complexity leadership: a healthcare imperative', Nursing Forum, Vol. 47, No. 4, pp.268-277, http://dx.doi.org /oi:10.1111/j.1744-6198.2012.00276.x.

Wilber, K. (2000) A Theory of Everything: An Integral Vision for Business, Politics, Science, and Spirituality, Shambhala Publications, Boston.

Yang, Y., May, A.J. and Yang, S.H. (2012) 'A generic state model with neighbourhood support from wireless sensor networks for emergency event detection', International Journal of Emergency Management, Vol. 8, No. 2, pp.135-152, http://dx.doi.org/10.1504/ IJEM.2012.046010.

Zagorecki, A.T., Johnson, D.E.A. and Ristvej, J. (2013) 'Data mining and machine learning in the context of disaster and crisis management', International Journal of Emergency Management, Vol. 9, No. 4, pp.351-365, http://dx.doi.org/10.1504/IJEM.2013.059879. 